\title{
A Physics based Model for Estimation of EGR Mass Flow Rate
}

\author{
Prashant M. Patane ${ }^{+*}$, Sudesh Powar ${ }^{\dagger}$ and Shailesh Deshmukh ${ }^{\dagger}$ \\ †Department of Mechanical Engineering, Savitribai Phule Pune University, MIT College of Engineering, Pune India \\ Accepted 02 March 2016, Available online 15 March 2016, Special Issue-4 (March 2016)
}

\begin{abstract}
The exhaust gas recirculation (EGR) is widely used to reduce $N O_{x}$ emissions in diesel engines. However an excessive EGR rate in the cylinders leads to reduction of $\mathrm{NO}_{x}$ and increment of particulate matter (PM) or misfire. In order to overcome this problem, the EGR mass flow rate should be controlled precisely. To control the EGR mass flow rate accurately, the EGR mass flow rate should be estimated correctly. This paper presents a physics based model of Variable Geometry Turbocharged diesel engine to estimate EGR mass flow rate. The diesel engine model includes subsystems of intake manifold model, exhaust manifold model, variable geometry turbocharger model, effective area for EGR valve model and exhaust gas temperature model. Models of the individual subsystem are implemented in MATLABTM/SIMULINKTM environment. These models are coupled together to form overall model for EGR mass flow rate estimation for variable geometry turbocharged diesel engine. Experimental data available from testing is used for simulation. Most of model is based on fundamental laws of physics and hence generic. The overall model has five inputs i.e. engine speed, fuel supply rate, intake manifold temperature, percentage VGT opening and EGR valve opening. The output of model is EGR mass flow rate and EGR ratio. Typical step input is provided to the engine model to study effects on output variables. The model is simulated for transient engine operating condition by sudden increasing or decreasing engine speed at different loading conditions. The estimated EGR mass flow rate and EGR ratio are found to be in acceptable range.
\end{abstract}

Keywords: Exhaust gas recirculation, Variable geometry turbocharger, Engine speed, Nitrogen oxide, Particulate matter

\section{Introduction}

The emission problem is one of the most interesting challenges in automotive technology and it is reached at alarming level. Because exhaust pollutants emitted to atmosphere by automobiles are the serious hygienic and environmental risk and the main source of air pollution, particularly in developing countries, the greatest interest and attention was devoted to use an effective technique to reduce the level of these pollutants. So research on improving the engine fuel economy and reducing exhaust emissions has become imperative in combustion and engine development.

The diesel engine exhaust gases contains oxides of nitrogen (Nitric oxide (NO), and small amounts of nitrogen dioxide $\left(\mathrm{NO}_{2}\right)$ - collectively known as $\left.\mathrm{NO}_{\mathrm{X}}\right)$, carbon monoxide (CO), carbon dioxide $\left(\mathrm{CO}_{2}\right)$, hydrocarbons ( $\mathrm{HC}$ ) and particulate matter (PM) etc. These emissions can be controlled by using aftertreatment processes such as Particulate filters, $\mathrm{NO}_{\mathrm{X}}$ trap, diesel particulate filter (DPF) or Selective Catalyst Reactor (SCR) systems are used but benefits of these after-treatment systems have nevertheless penalties

*Corresponding author: Prashant M. Patane on engine performance, fuel consumption and on engine cost. So different techniques are used to reduce some of these emissions. The nitrogen oxides $\left(\mathrm{NO}_{\mathrm{x}}\right)$ is reduced by using Exhaust Gas Recirculation (EGR) system.

EGR is an established primary emission control technique for the effective suppression of NOx emissions in the reciprocating internal combustion (IC) engines. EGR is not a new system and literature is already quite abundant on this topic. Decreasing of NOx emissions is achieved by a heat absorption by triatomic molecules such as $\mathrm{CO}_{2}$ and $\mathrm{H}_{2} \mathrm{O}$. On the other hand, the maximal EGR rate is limited by a significant increase of the particle emission (PM). Moreover, additional disadvantages of the high EGR rates are on the peak cylinder pressure, compressor work and increased wear of piston ring, cylinder liner, bearings and valve train.

To achieve the EURO IV and EURO V levels, an increased amount of the exhaust recirculated gas with cooling circuit is necessary. A homogenous Air-EGR mixture and a precise control of the EGR distribution for each cylinder enable lower nitrogen oxide emissions without the penalty of sudden increased particulate emissions. Therefore, the whole EGR 
control strategy is a question of compromise among EGR rate- engine load - consumption - performance NOx emissions - PM emissions.

The sensors can be used directly for measuring the mass flow rate of EGR directly but the cost of such sensor is very high i.e. the cost becomes more than the cost of car itself. So it is not possible to mount the sensors for EGR mass flow rate estimation by sensors. So considering the $\mathrm{NO}_{\mathrm{x}}$ emission regulations and high cost of sensors the a physics based model is developed for accurate estimation of EGR concentrations of the gas that enters the combustion chamber in order to properly control the engine parameters that have EGR dependency, especially those affecting combustion stability.

\section{Introduction}

The model is developed for four cylinder four stroke water-cooled turbocharged diesel engine with common rail direct injection (CRDI) system. The intention of choosing this engine is because it is having all the latest developments which compatible to EURO IV norms. The engine is fitted with exhaust gas recirculation (EGR) and variable geometry turbocharger (VGT) with charge intercooler. The EGR system is provided with EGR valve, EGR cooler and EGR pipe with continuously variable EGR valve. The valve is controlled through electronic control unit (ECU). The engine is fitted with diesel oxidation catalytic converter meant for reducing exhaust pollution. The schematic of engine setup is shown in Figure [1].

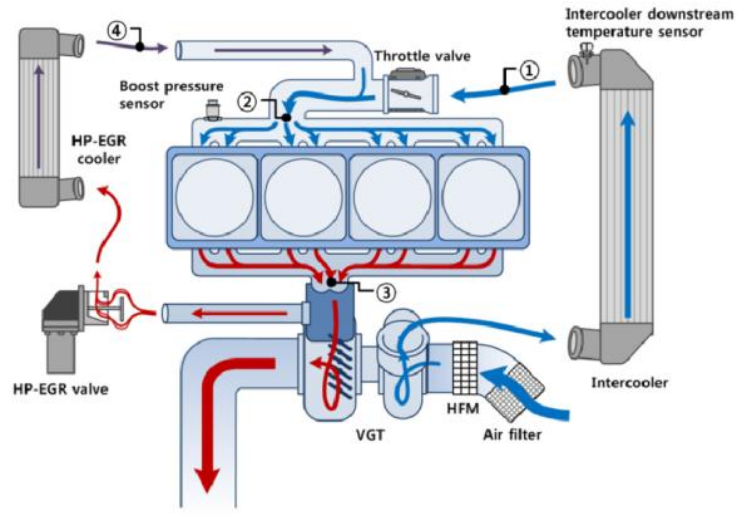

Figure 1 - Schematic of a Variable Geometry Turbocharged diesel engine showing major subsystems

The engine specifications are given below in Table 1.

Table 1 - Specification of engine under test

\begin{tabular}{|c|c|}
\hline Maximum engine power & 70 Ps @ 4000 rpm \\
\hline Maximum torque & $140 \mathrm{NM} \mathrm{@} \mathrm{1800} \mathrm{rpm}$ \\
\hline Total displacement volume & $1390 \mathrm{cc}$ \\
\hline Bore & $75 \mathrm{~mm}$ \\
\hline Stroke length & $79 \mathrm{~mm}$ \\
\hline Compression ratio & $18.5: 1$ \\
\hline Firing order & $1-3-4-2$ \\
\hline
\end{tabular}

\section{Development of Non linear Model}

A variable geometry turbocharged, common rail direct injection with EGR and EGR cooler system diesel engine is selected for the present study, which is used for passenger car applications. The schematic of the engine setup is shown in Figure [1] and its specifications are given in the Table-1. For obtaining the complete model, the engine was divided into five major subsystems viz., EGR valve model, variable geometry turbocharger model, intake manifold pressure model, exhaust manifold pressure model and exhaust manifold temperature model. Each subsystem is then modeled individually. A set of differential equations of the subsystems, viz., variable geometry turbocharger, intake manifold and exhaust manifold of the engine represent the dynamics of the engine system as a whole.

\section{EGR model}

The EGR valve used on the test engine is EVRV (Electronic Vacuum Regulator Valve ) which is solenoid operated valve. The EGR is connected from the exhaust manifold to intake manifold through EGR cooler. The EGR valve is operated by command from ECU. It is held closed by spring pressure and lifted by vacuum pressure from the Electronic Vacuum Regulator (EVR) allowing exhaust gas to enter the inlet system by its own pressure, replacing some of the oxygen in the inlet manifold. The EGR valve is a duty cycled valve, meaning that it has a variable opening and closing, controlled by the EVR, to provide the required gas flow. The EGR valve lift with respect to actuation pressure which is obtain from engine manufacturer is given in Table-2.

Table 2 - EGR valve lift with respect to actuation pressure.

\begin{tabular}{|c|c|}
\hline Actuation pressure & Valve lift \\
\hline $300 \mathrm{mbar}$ & $0.5 \mathrm{~mm}$ \\
\hline $450 \mathrm{mbar}$ & $4 \mathrm{~mm}$ \\
\hline
\end{tabular}

The mass flow through the EGR-valve is modeled as simplification of compressible flow through restriction with variable area Heywood et al. and with assumption that there is no reverseflow when $P_{\text {em }}<P_{i m}$. The motive for thisassumption is to construct a simple model. The model can be extended with reverse flow, but this increases the complexity of the model since a reverse flow model requires mixing of different temperatures and oxygen fractions in the exhaust manifold and a change of the temperature and the gas constant in the EGR mass flow model. However, pressure in exhaust manifold $\left(P_{e m}\right)$ is larger than pressure in intake manifold $\left(P_{i m}\right)$ in normal operating points, consequently assumption above will not affect the model behavior in these operating points. Furthermore, reverse flow is not measured and can 
therefore not be validated Hyunjun Leeet al. The mass flow through EGR valve is given by,

$\dot{m}_{e g r}= \begin{cases}C_{d} A_{\text {eff }} \frac{P_{e m}}{\sqrt{T_{e m} R}} \Psi\left(\frac{P_{i m}}{P_{e m}}\right) & \text { if } P_{i m}<P_{e m} \\ 0 & \text { if } P_{i m}=P_{e m} \\ C_{d} A_{e f f} \frac{P_{i m}}{\sqrt{T_{i m} R}} \Psi\left(\frac{P_{e m}}{P_{i m}}\right) & \text { if } P_{i m}>P_{e m}\end{cases}$

The pressure correction factor is given by,

$$
\begin{aligned}
& \Psi\left(\frac{P_{i m}}{P_{e m}}\right) \\
& = \begin{cases}\sqrt{\gamma}\left(\frac{2}{\gamma+1}\right)^{\frac{\gamma+1}{2(\gamma-1)}} & \text { if } \frac{P_{i m}}{P_{e m}} \leq\left(\frac{2}{\gamma+1}\right)^{\frac{\gamma}{\gamma-1}} \\
\sqrt{\frac{2 \gamma}{\gamma-1}\left(\left(\frac{P_{i m}}{P_{e m}}\right)^{2 / \gamma}-\left(\frac{P_{i m}}{P_{e m}}\right)^{(\gamma+1) / \gamma}\right)} \text { if } \frac{P_{i m}}{P_{e m}}>\left(\frac{2}{\gamma+1}\right)^{\frac{\gamma}{\gamma-1}}\end{cases}
\end{aligned}
$$

Where,

$C_{d}=$ Coefficient of discharge $=0.95$

$A_{\text {eff }}=$ Effective area for EGR mass flow rate $\left(\mathrm{m}^{2}\right)$

$\mathrm{P}_{\mathrm{em}}=$ Pressure in exhaust manifold $(\mathrm{pa})$

$\mathrm{P}_{\mathrm{im}}=$ Pressure in intake manifold (pa)

$\mathrm{T}_{\mathrm{em}}=$ Temperature in exhaust manifold $(\mathrm{K})$

$\mathrm{T}_{\mathrm{im}}=$ Temperature in intake manifold $(\mathrm{K})$

$\mathrm{R}=$ Exhaust gas constant $(\mathrm{J} / \mathrm{Kg}-\mathrm{K})$

$\Psi=$ Pressure ratio correction factor

\section{EGR valve effective area $\left(A_{\text {eff }}\right)$ model}

By geometry of valve the total valve lift is $4 \mathrm{~mm}$ and is divided into 2 parts i.e. initial $1 \mathrm{~mm}$ and from $1 \mathrm{~mm}$ to $4 \mathrm{~mm}$. To obtain the effective are for EGR valve during its opening and closing, the EGR valve is taken out and measurements are taken on CMM machine. The front view and sectional cut of EGR valve is given in Figure 2.
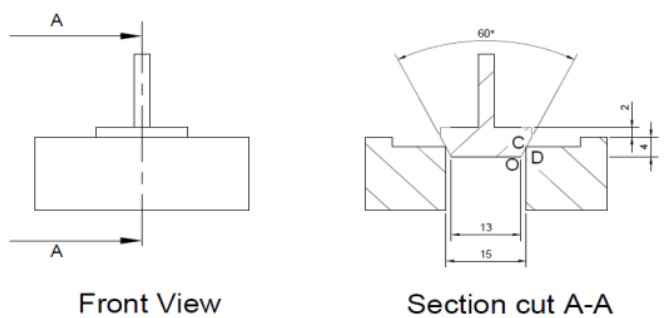

Figure 2 - Front view and section cut of EGR valve when valve is at rest

\section{Equation for effective area of EGR valve opening during initial $1 \mathrm{~mm}$ of valve lift}

For the valve lift up to $1 \mathrm{~mm}$ travel creates effective area of EGR valve like disc. So the effective area of EGR valve opening during initial $1 \mathrm{~mm}$ of valve lift is given by,
$A_{e f f}=\pi\left(R_{2}^{2}-\left(R_{2}-\frac{0.73+\delta}{1.73}\right)^{2}\right)$

Equation for effective area of EGR valve opening from $1 \mathrm{~mm}$ to $4 \mathrm{~mm}$ of valve lift:

The valve lift from $1 \mathrm{~mm}$ to $4 \mathrm{~mm}$ travel creates effective area of EGR valve like frustum of cone. So the effective area of EGR valve opening from $1 \mathrm{~mm}$ to $4 \mathrm{~mm}$ valve lift is given by,

$A_{\text {eff }}=\pi\left(R_{1}+R_{2}\right) \sqrt{\left(R_{1}-R_{2}\right)^{2}+\delta^{2}}$

$\mathrm{R}_{1}=6.5 \mathrm{~mm}$ and $\mathrm{R}_{2}=7.5 \mathrm{~mm}$

The variation of effective opening area of EGR valve $\left(A_{\text {eff }}\right)$ at different valve positions $(\delta)$ is shown in Figure 3. It is seen that as valve opening increases the $A_{\text {eff }}$ increases.

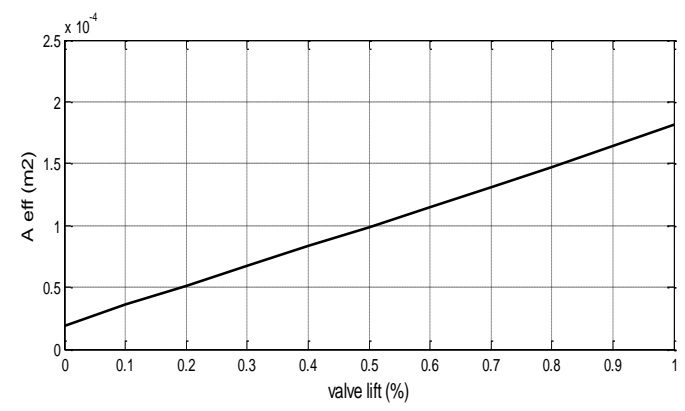

Figure 3 - Effective area of EGR valve $\left(A_{\text {eff }}\right)$ at different valve positions

The EGR mass flow rate model, modeled in SIMULINK is given by,

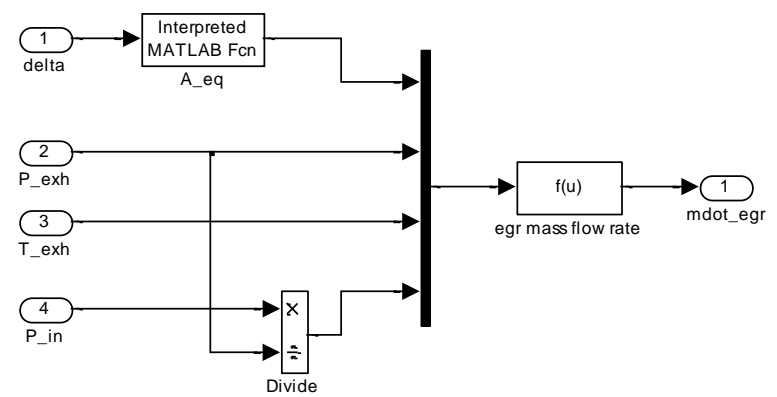

Figure 4 - Simulink model for EGR mass flow rate

\section{Variable Geometry Turbocharger (VGT) model}

The standard steady state performance of compressor and turbine maps are available from the manufacturer. The mass flow rate through compressor $\left(\dot{m}_{c}\right)$, and efficiency of compressor $\left(\eta_{c}\right)$, are curve fitted using pressure ratio across compressor $\left(P R_{c}\right)$ and 
turbocharger rotor speed $\left(N_{t c}\right)$. Similarly mass flow rate through turbine $\left(\dot{m}_{t}\right)$, and efficiency of turbine $\left(\eta_{t}\right)$, are curve fitted using VGT position $\left(u_{v g t}\right)$, and pressure ratio across turbine $\left(P R_{t}\right)$ and turbocharger rotor speed $\left(N_{t c}\right)$. The turbocharger shaft speed is given by Newton's second law of motion Malkhede et al.

$J_{t c} \frac{d \omega_{t c}}{d t}=M_{t}-M_{c}-M_{r}$

$=M_{t}-M_{c}$

Where, $\mathrm{M}_{\mathrm{t}}, \mathrm{M}_{\mathrm{c}}$ and $\mathrm{M}_{\mathrm{r}}$ are turbine, compressor and bearing friction torque (N.m) and moment of inertia of turbocharger rotor is denoted by $\mathrm{J}_{\mathrm{tc}}$ in $\left(\mathrm{Kg} \cdot \mathrm{m}^{2}\right)$. Bearing friction torque $\mathrm{M}_{\mathrm{r}}$ is often negligible.

\section{Estimation of compressor torque}

The steady state compressor performance data provided by the manufacturer is used to determine mass flow rate of air $\left(\dot{m}_{c}\right)$, and efficiency of the compressor $\left(\eta_{c}\right)$. The mass flow of air and efficiency of compressor are fitted as function of pressure ratio across compressor $\left(P R_{c}\right)$ and turbocharger speed $\left(N_{t c}\right)$. The compressor map is provided by manufacturer with the reference values $P_{\text {ref }}=$ $100000 \mathrm{pa}$, and $T_{r e f}=298 \mathrm{~K}$. So that these values can be used for determining mass flow rate of air $\left(\dot{m}_{c}\right)$ and efficiency of compressor $\left(\eta_{c}\right)$. Actual mass flow rate is simulated in MATLAB by forming the equations of mass flow rate and efficiency as function of turbo speed and pressure ratio across compressor. So the actual air mass flow rate and efficiency of compressor is obtained from compressor data as,

$$
\dot{m}_{c}=f_{1}\left(P R_{c}, N_{t c}\right) \eta_{c}=f_{2}\left(P R_{c}, N_{t c}\right)
$$

Where,

$\mathrm{PR}_{c}=$ Pressure ratio across compressor

$\mathrm{N}_{\mathrm{tc}}=$ Turbocharger speed (rpm)

$\dot{m}_{c}=$ Mass flow rate through compressor $(\mathrm{Kg} / \mathrm{s})$

$\eta_{\mathrm{c}}=$ Efficiency of compressor

The function $f_{1}$ and $f_{2}$ represents compressor mass flow rate and efficiency of compressor. The simulation of mass flow rate through compressor and efficiency of compressor is done in SIMULINK as shown in Figure 5. The compressor torque is given by applying first law of thermodynamics Malkhede et al,

$M_{c}=\frac{\dot{m}_{c} C p_{a}}{\omega_{t c}}\left[\frac{1}{\eta_{c}} T_{a}\left(\left(\frac{p_{c}}{p_{a}}\right)^{\frac{\gamma-1}{\gamma}}-1\right)\right]$

Where,

$\dot{m}_{c}=$ Mass flow rate through compressor $(\mathrm{Kg} / \mathrm{s})$

$\eta_{c}=$ Efficiency of compressor

$\mathrm{Cpa}=$ Specific heat of air (J/Kg.K)

$\omega_{\mathrm{tc}}=$ Angular speed of turbocharger $(\mathrm{rad} / \mathrm{s})$
$\mathrm{T}_{\mathrm{amb}}=$ Ambient temperature $(\mathrm{K})$

$\mathrm{P}_{\mathrm{c}}=$ Pressure after compressor $(\mathrm{Pa})$

$\mathrm{P}_{\mathrm{amb}}=$ Ambient pressure $(\mathrm{Pa})$

$\gamma=$ Specific heat ratio of air

The estimated data for compressor mass flow rate and compressor efficiency verses actual compressor mass flow rate and compressor efficiency at different pressure ratio and turbocharger speed are plotted in Figure 5 and Figure 6 respectively.

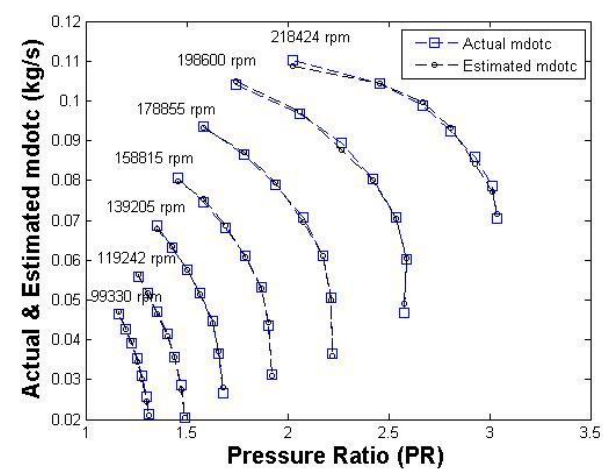

Figure 5 - Actual Vs estimated compressor mass flow rate $(\mathrm{kg} / \mathrm{s})$

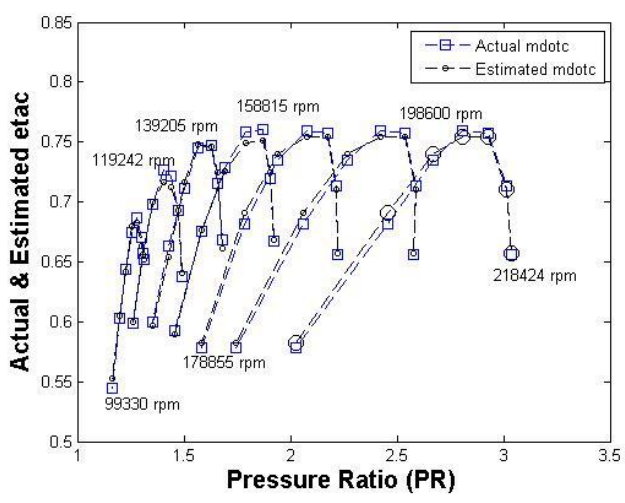

Figure 6 - Actual Vs estimated compressor efficiency After comparing actual mass flow rate and efficiency from compressor map verses estimated mass flow rate and compressor efficiency, the overall percentage root mean square error occurred is $1.58 \%$ and $1.05 \%$ respectively shown in Figure 7 and Figure 8.

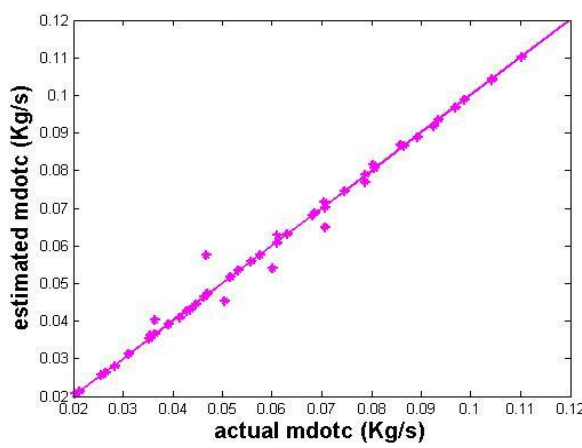

Figure 7 - Relative error between actual and estimated compressor mass flow rate $(\mathrm{kg} / \mathrm{s})$ 


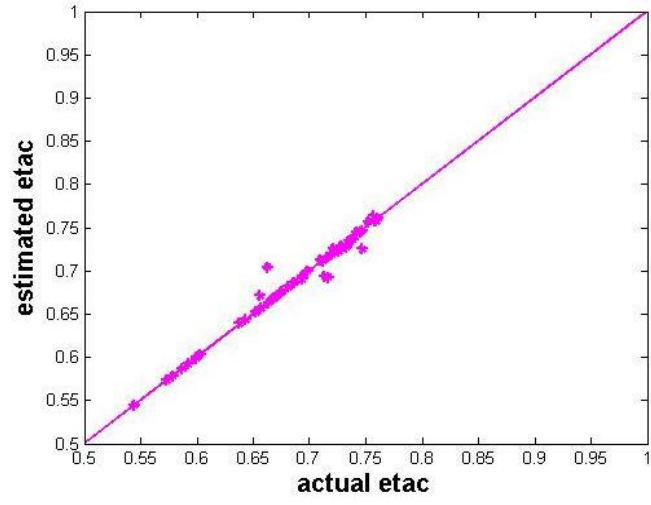

Figure 8 - Relative error between actual and estimated compressor efficiency

\section{Estimation of turbine torque:}

Similarly to the compressor model, the steady state turbine performance data provided by the manufacturer is used to determine mass flow rate through turbine $\left(\dot{m}_{t}\right)$, and efficiency of the turbine $\left(\eta_{t}\right)$. The mass flow rate through turbine and efficiency of turbine are fitted as function of pressure ratio across turbine $\left(\mathrm{P} R_{t}\right)$, turbocharger speed $\left(N_{t c}\right)$ and VGT position $\left(u_{v g t}\right)$. The mass flow rate is simulated in MATLAB by forming the equations of mass flow rate and efficiency as function of pressure ratio across turbine, turbo speed and VGT position. So the actual air mass flow rate is obtained from turbine data as,

$\dot{m}_{t}=f_{3}\left(P R_{t}, N_{t c}, u_{v g t}\right)$

$\eta_{t}=f_{4}\left(P R_{t}, N_{t c}, u_{v g t}\right)$

Where,

$\dot{m}_{t}=$ Mass flow rate through turbine $(\mathrm{Kg} / \mathrm{s})$

$\mathrm{PR}_{\mathrm{t}}=$ Pressure ratio across turbine

$N_{t c}=$ Turbocharger speed (rpm)

$u_{v g t}=$ VGT position

$\eta_{t}=$ Efficiency of turbine

The function $f_{3}$ and $f_{4}$ is represents turbine mass flow rate and efficiency of turbine respectively. The turbine torque is given by applying first law of thermodynamics Malkhede et al.

$M_{t}=\frac{\eta_{t} \dot{m}_{t} C p_{\text {exh }} T_{\text {exh }}}{\omega_{t c}}\left[1-\left(\frac{p_{\text {exh }}}{p_{a}}\right)^{\frac{1-n_{\text {exh }}}{n_{\text {exh }}}}\right]$

Where,

$\dot{m}_{t}=$ Mass flow rate through turbine $(\mathrm{Kg} / \mathrm{s})$

$\eta_{t}=$ Efficiency of turbine
$\mathrm{Cp}_{\mathrm{ex}}=$ Specific heat of exhaust gas $(\mathrm{J} / \mathrm{Kg} . \mathrm{K})$

$\mathrm{W}_{\mathrm{tc}}=$ Angular speed of turbocharger $(\mathrm{rad} / \mathrm{s})$

$\mathrm{T}_{\mathrm{exh}}=$ Exhaust temperature $(\mathrm{K})$

$\mathrm{P}_{\text {exh }}=$ Exhaust pressure $(\mathrm{Pa})$

$n_{\text {exh }}=$ Specific heat ratio of exhaust gas

The estimated data for turbine mass flow rate and turbine efficiency verses actual turbine mass flow rate and turbine efficiency at different pressure ratio, turbocharger speed and VGT positions are plotted in Figure 9 and Figure 10 respectively.

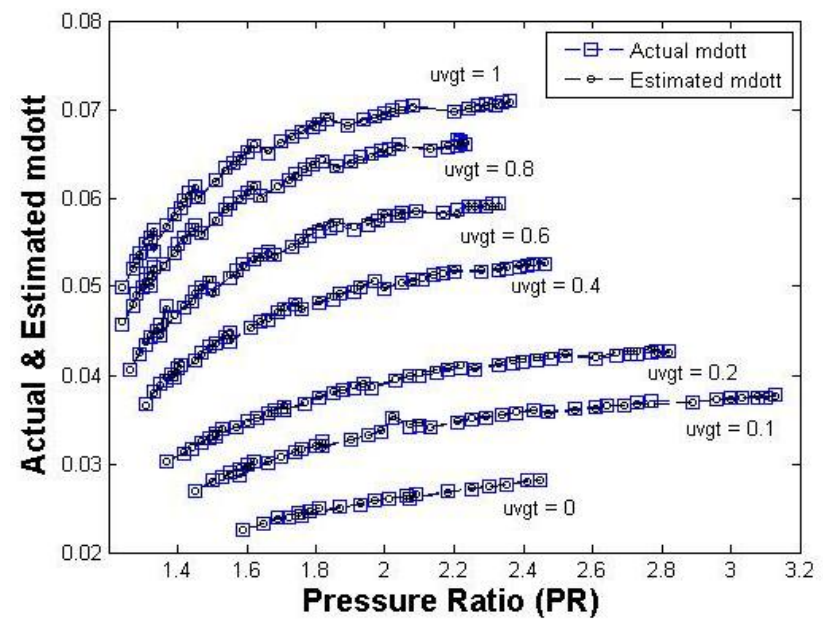

Figure 09- Actual Vs estimated turbine mass flow rate (kg/s).

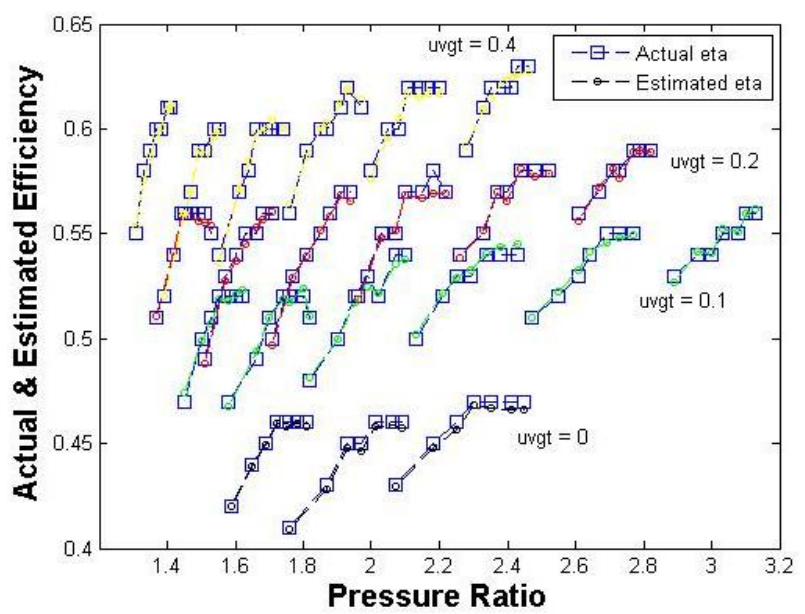

Figure 10 - Actual Vs estimated turbine efficiency

After comparing actual mass flow rate and efficiency from turbine map verses estimated mass flow rate and efficiency of turbine, the overall percentage root mean square error occurred is $0.19 \%$ and $0.4 \%$ respectively shown in Figure 11 and Figure 12. 


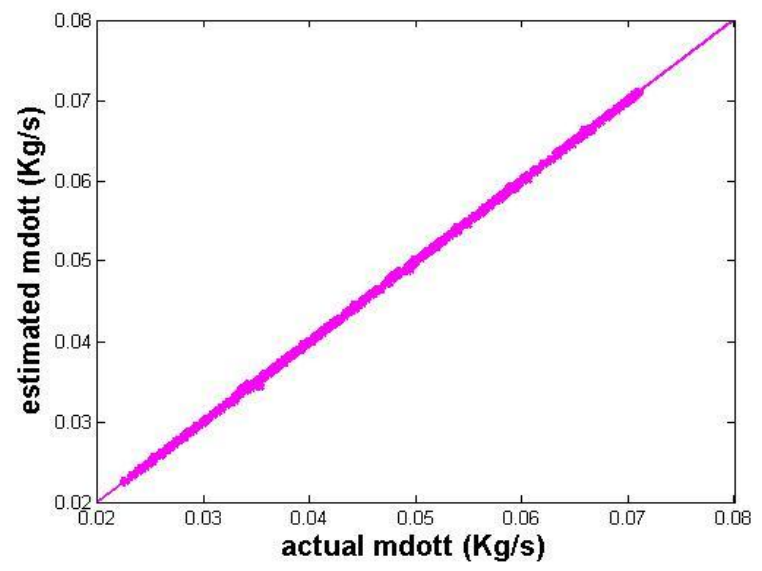

Figure 11 - Relative error between actual and estimated turbine mass flow rate $(\mathrm{kg} / \mathrm{s})$

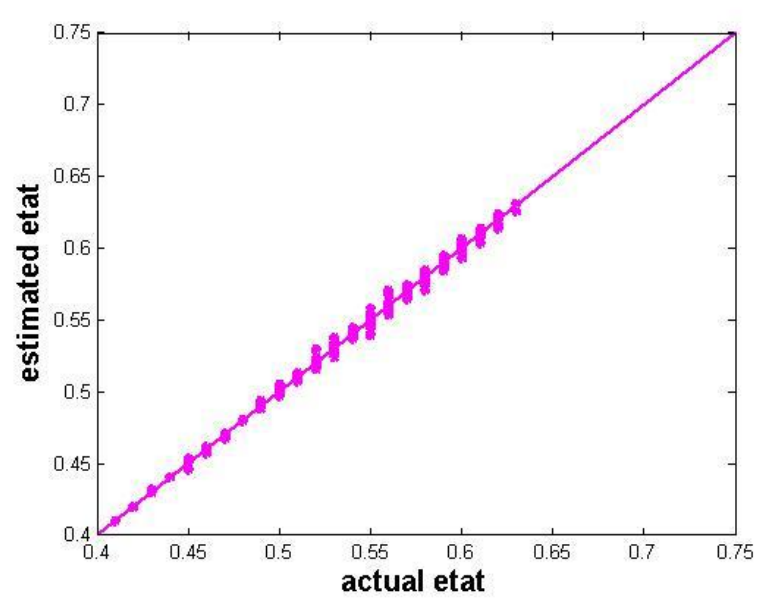

Figure 12 - Relative error between actual and estimated turbine efficiency

\section{Intake manifold model}

The intake manifold is a small but important part of the engine. Engine models are often based on mass flow through the engine. The mass flow rate is important to engine performance since the amount of air inducted into the cylinders to a large extent governs the amount of fuel that can be burned and therefore power output. The intake manifold dynamics are presented by considering ideal gas equation and mass conservation principle. The dynamics is determined from filling and emptying method which gives pressure state equation given below by following equationAmmannet al.

$\frac{d P_{i m}}{d t}=\frac{\gamma R}{V_{i m}}\left(\dot{m}_{i c} T_{i c}+\dot{m}_{e g r} T_{e g r}-\dot{m}_{i e} T_{\mathrm{i} e}\right)$

Where,

$\mathrm{P}_{\mathrm{im}}=$ Intake manifold pressure $(\mathrm{Pa})$

$\mathrm{V}_{\mathrm{im}}=$ Intake manifold volume $\left(\mathrm{m}^{3}\right)$ $\dot{m}_{i c}, T_{i c}=$ Mass flow rate $(\mathrm{Kg} / \mathrm{s})$ and temperature after intercooler $(\mathrm{K})$

$\dot{m}_{\text {egr }}, T_{\text {egr }}=$ Mass flow rate $(\mathrm{Kg} / \mathrm{s})$ and temperature after egrcooler $(\mathrm{K})$

$\dot{m}_{i e}, T_{i e}=$ Mass flow rate $(\mathrm{Kg} / \mathrm{s})$ and temperature of air from intake manifold to engine $(\mathrm{K})$

$R=287$; Gas constant of air (J/Kg.K)

The mass flow rate from compressor is obtained from function $f_{1}$ as discussed in compressor model. The intercooler is next to the compressor, so mass flow rate from intercooler is same as that of compressor. The mass flow rate through compressor is given by,

$\dot{m}_{c}=f_{1}\left(P R_{c}, N_{t c}\right)$

The outlet temperature of compressor is given by assuming compression to be isentropic. And it is given by following Equation,

$T_{c}=T_{a}\left[1+\frac{1}{\eta_{c}}\left(\left(P R_{c}\right)^{\frac{\gamma-1}{\gamma}}-1\right)\right]$

Where,

$\mathrm{T}_{\mathrm{c}}=$ Compressor outlet temperature $(\mathrm{K})$

$\gamma=$ Ratio of specific heat of air

The outlet temperature of intercooler is modeled as heat exchanger. The outlet temperature of the intercooler is calculated using following Equation,

$T_{i c}=T_{c}\left(1-\varepsilon_{i c}\right)+\varepsilon_{i c} T_{a}$

Where,

$\mathrm{T}_{\mathrm{ic}}=$ Temperature after intercooler $(\mathrm{K})$

$\varepsilon_{i c}=$ Effectiveness of intercooler $=0.55$

The mass flow rate through EGR valve is obtained as discussed in previous EGR model. The outlet temperature of egrcooler is modeled as heat exchanger. The outlet temperature of egrcooler is calculated using following Equation,

$T_{\text {egr }}=T_{\text {exh }}\left(1-\varepsilon_{\text {egrcooler }}\right)+\varepsilon_{\text {egrcooler }} T_{c w}$

Where,

$\mathrm{T}_{\text {egr }}=$ Egrcooler outlet temperature $(\mathrm{K})$

$\mathrm{T}_{\text {exh }}=$ Exhaust temperature $(\mathrm{K})$

$\mathrm{T}_{\mathrm{cw}}=$ Cooling water temperature $(\mathrm{K})$

$\varepsilon_{\text {egrcooler }}=$ Effectiveness of egrcooler $=0.85$

The mass flow rate from intake manifold to engine $\left(\dot{m}_{i e}\right)$ is given by Speed-density equation. And it is given by following Equation,

$\dot{m}_{i e}=\eta_{\mathrm{v}} \times \frac{P_{i m}}{R T_{i e}} \times V_{D} \times \frac{N_{e}}{120}$ 
Where,

$\dot{m}_{i e}=$ Mass flow rate from intake manifold to engine (Kg/s)

$\eta_{\mathrm{v}}=$ Volumetric efficiency

$\mathrm{T}_{\mathrm{ie}}=$ Temperature in intake manifold $(\mathrm{K})$

$\mathrm{N}_{\mathrm{e}}=$ Engine speed (rpm)

$V_{D}=\left(V_{s} \times n\right)=$ Engine displaced volume $\left(\mathrm{m}^{3}\right)$

$\mathrm{V}_{\mathrm{S}}=\left((\pi / 4) \mathrm{D}^{2} \mathrm{~L}\right)=$ Swept volume per cylinder $\left(\mathrm{m}^{3}\right)$

$\mathrm{D}=$ Cylinder bore $(\mathrm{mm})$

$\mathrm{L}=$ Stroke length $(\mathrm{mm})$

$n=4$; Number of cylinders

The volumetric efficiency $\left(\eta_{v}\right)$, is a measure of engine's ability to draw air into cylinders. The volumetric efficiency of engine is curve fitted as function of engine speed $\left(N_{e}\right)$. The estimated volumetric efficiency for a given engine speed is given by Equation,

$\eta_{v}=0.935+0.355 \times 10^{-4} N_{e}-1.01 \times 10^{-8}\left(N_{e}\right)^{2}$

The intake manifold temperature $\left(T_{i e}\right)$, is measured directly by using sensor mounted on intake manifold after EGR mixing point close to cylinder.

\section{Exhaust manifold model}

The exhaust manifold dynamics is like the intake manifold dynamics considers ideal gas laws and law of conservation of masses Ammannet al. Thus the exhaust manifold dynamics is given by Equation,

$\frac{d P_{e x h}}{d t}=\frac{n_{e x h} R_{e x h}}{V_{e m}}\left(\dot{m}_{e e} T_{e x h}-\dot{m}_{e g r} T_{e g r}-\dot{m}_{t} T_{t}\right)$

Where,

$\mathrm{P}_{\text {exh }}=$ Exhaust manifold pressure $(\mathrm{Pa})$

$\mathrm{V}_{\text {exh }}=$ Exhaust manifold volume $\left(\mathrm{m}^{3}\right)$

$\mathrm{R}_{\text {exh }}=289.7$; Exhaust Gas constant $(\mathrm{J} / \mathrm{Kg} . \mathrm{K})$

$\dot{m}_{e e}, T_{e x h}=$ Mass flow rate $(\mathrm{Kg} / \mathrm{s})$ and temperature $(\mathrm{K})$ after engine exhaust

$\dot{m}_{t}, T_{t}=$ Mass flow rate $(\mathrm{Kg} / \mathrm{s})$ and temperature $(\mathrm{K})$ after turbine outlet

$n_{\text {exh }}=$ Polytropic index for exhaust gas

The mass flow rate from engine exhaust manifold $\left(\dot{m}_{e e}\right)$, is determined as sum of mass flow rate of air $\left(\dot{m}_{i e}\right)$ and mass flow rate of fuel $\left(\dot{m}_{f}\right)$ that take part in the combustion. The mass flow rate of fuel can measured directly by fuel consumption meter and mass flow rate of air from intake manifold to engine is given by using speed density equation as discussed before. Thus mass flow rate from engine exhaust manifold is given by Equation, $\dot{m}_{e e}=\dot{m}_{i e}+\dot{m}_{f}$

The mass flow rate through egr valve $\left(\dot{m}_{\text {egr }}\right)$ and temperature after egrcooler $\left(T_{\text {egr }}\right)$ is same as discussed in previous EGR model and intake manifold model respectively. And the temperature in intake manifold $\left(T_{i e}\right)$ is measured directly by using sensor mounted on intake manifold after egr mixing. The mass flow rate through turbine $\left(\dot{m}_{t}\right)$ is given by function $f_{3}$ as discussed in previous section. The mass flow rate through turbine is given by,

$\dot{m}_{t}=f_{3}\left(P R_{t}, N_{t c}, u_{v g t}\right)$

The outlet temperature of turbine is determined by assuming expansion over turbine is isentropic. Thus the outlet temperature of turbine is given by Equation,Ammannet al.

$T_{t}=T_{e x h}-T_{e x h} \eta_{t}\left[1-\left(P R_{t}\right)^{\left(\frac{1-n_{e x h}}{n_{e x h}}\right)}\right]$

Where,

$\mathrm{T}_{\mathrm{t}}=$ Turbine outlet temperature $(\mathrm{K})$

$\mathrm{T}_{\text {exh }}=$ Exhaust temperature $(\mathrm{K})$

$\mathrm{PR}_{\mathrm{t}}=$ Pressure ratio across turbine

$\eta_{\mathrm{t}}=$ Turbine efficiency

$\mathrm{n}_{\mathrm{exh}}=$ Polytropic index for exhaust gas

\section{Exhaust manifold temperature model:}

The exhaust temperature is the summation of inlet air temperature and temperature rise in engine. Heat transfer from exhaust manifold is not considered.

$T_{\text {exh }}=T_{i e}+\Delta T_{e}$

Where,

$\mathrm{T}_{\mathrm{ie}}=$ Temperature of incoming air $(\mathrm{K})$

$\Delta T_{e}=$ Temperature rise in engine

Engine temperature rise is considered to be largely a function of air fuel ratio. Horlock et al have given variation of engine temperature rise with $\mathrm{A} / \mathrm{F}$ ratio. The expression is valid for range if air-fuel ratio of 15 and higher. So the expression of temperature in engine is given by following equation,

$\Delta T_{e}=\operatorname{Exp}\left[7.57-7.1110^{-2}\left(\frac{A}{F}\right)+5.5510^{-4}\left(\frac{A}{F}\right)^{2}\right]$

Where,

$\mathrm{A} / \mathrm{F}=$ Air to fuel ratio

The all coupled model, considering variable geometry turbocharger model, intake and exhaust manifold model and exhaust temperature model, estimating the mass flow rate of EGR, through EGR valve modeled in SIMULINK is given Figure 


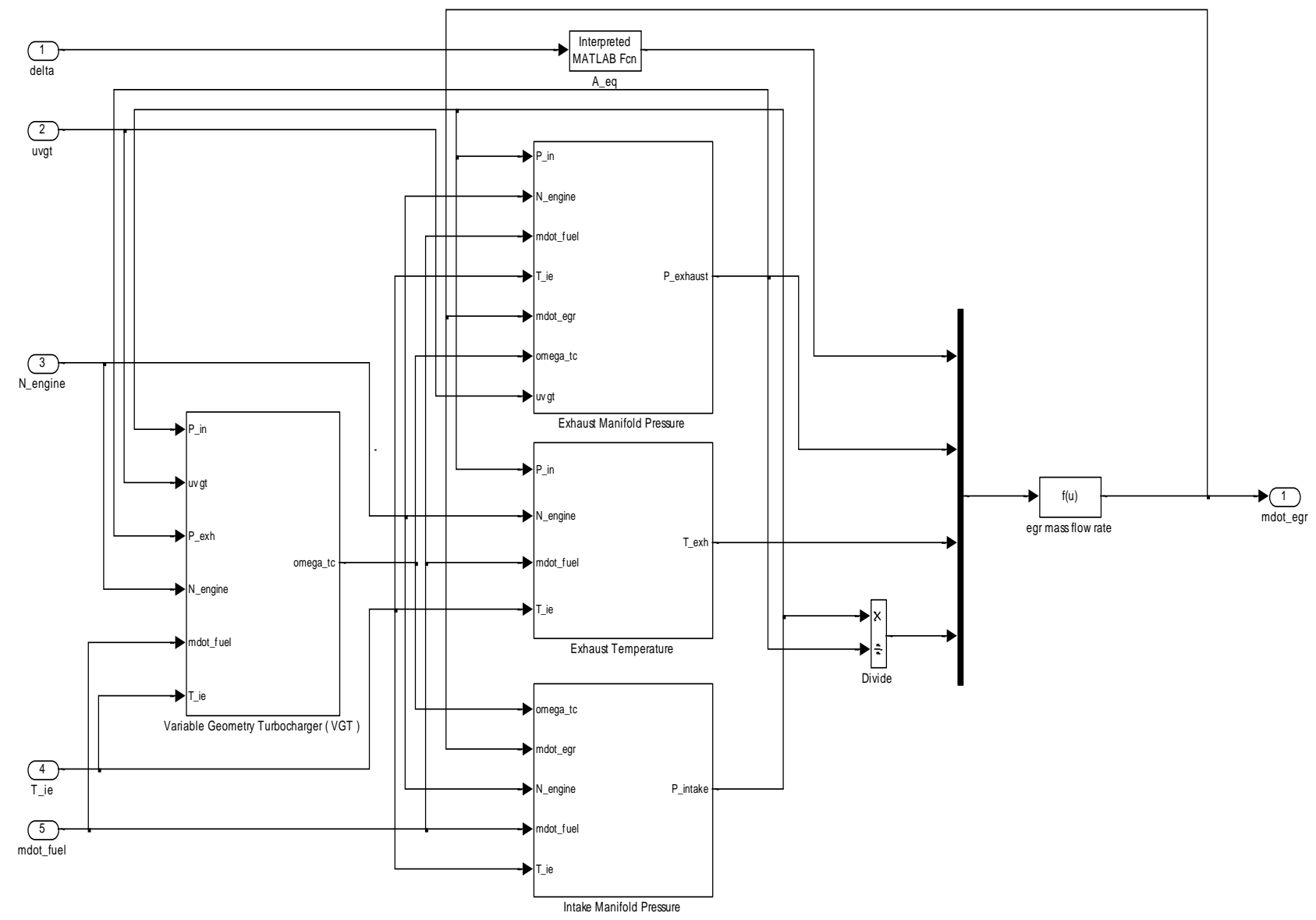

Figure 13 - Simulink model for EGR mass flow rate.

\section{Result and discussion}

The results of turbocharged diesel engine model developed are discussed in this chapter. The results of model are made using MATLAB ${ }^{\mathrm{TM}} /$ SIMULINK ${ }^{\mathrm{TM}}$ are discussed in section. MATLAB is high performance language for technical computing, integrates computation, visualization and programming in easy to use environment. Simulink has become most widely used software package in academic and industry for modeling and simulating dynamic systems. Simulation is carried out using ode 45 solver. Engine data which is used for simulation is given by manufacturer. The model is used to estimate EGR mass flow rate for turbocharged diesel engine. The overall model has five inputs i.e.. engine speed, fuel supply rate, intake manifold temperature, VGT position in percent and EGR valve opening in percent.

The testing is carried out at different loading condition i.e.. from 10 to $80 \%$. At particular constant load, engine speed is varied and corresponding fuel flow rate, intake manifold temperature and VGT position are measured. The same procedure is carried out at different loading condition.

Subsystem models, which are coupled together to formulate the overall turbocharged diesel engine model to estimate EGR mass flow rate is very complex and highly nonlinear. The effect of input on output is not straight forward. For this investigation, we have used the different loading condition and engine speed is varied step by step. The corresponding fuel supply rate, intake manifold temperature VGT position are measured from control panel. Figures 24 to 26 show the time histories of varies states. The inputs used are shown in each graph for reference. Simulation is allowed to run from 0 to 250 seconds. Brief discussion based on simulation results are given below.

\section{For $20 \%$ Loading}
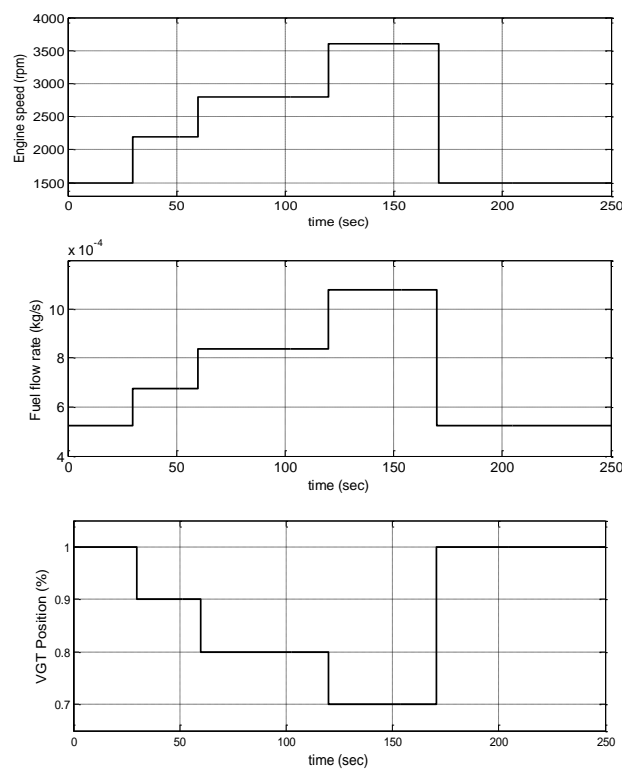

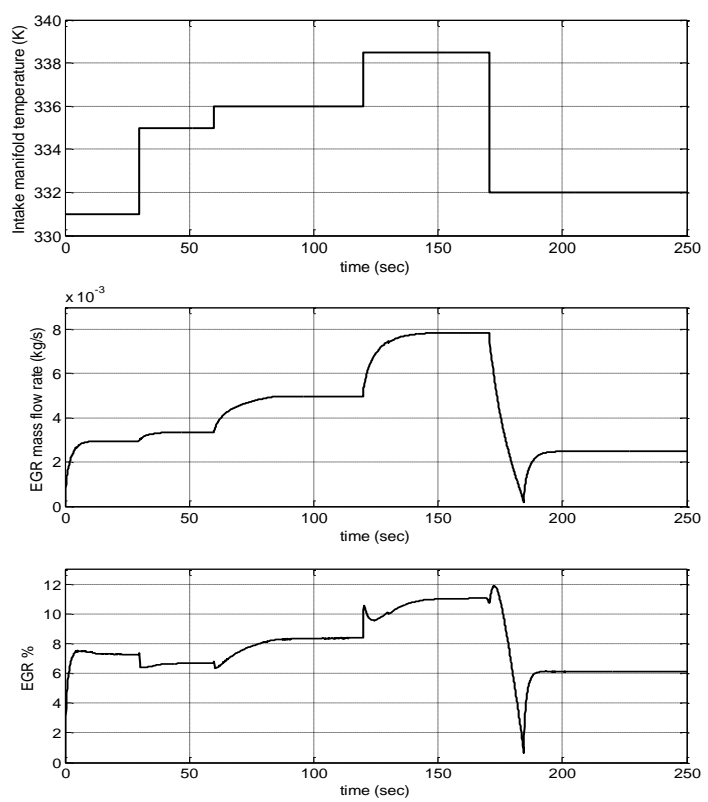

Figure 14 - At 20\% loading effect of variation of engine speed on EGR mass flow rate

\section{For $50 \%$ loading}
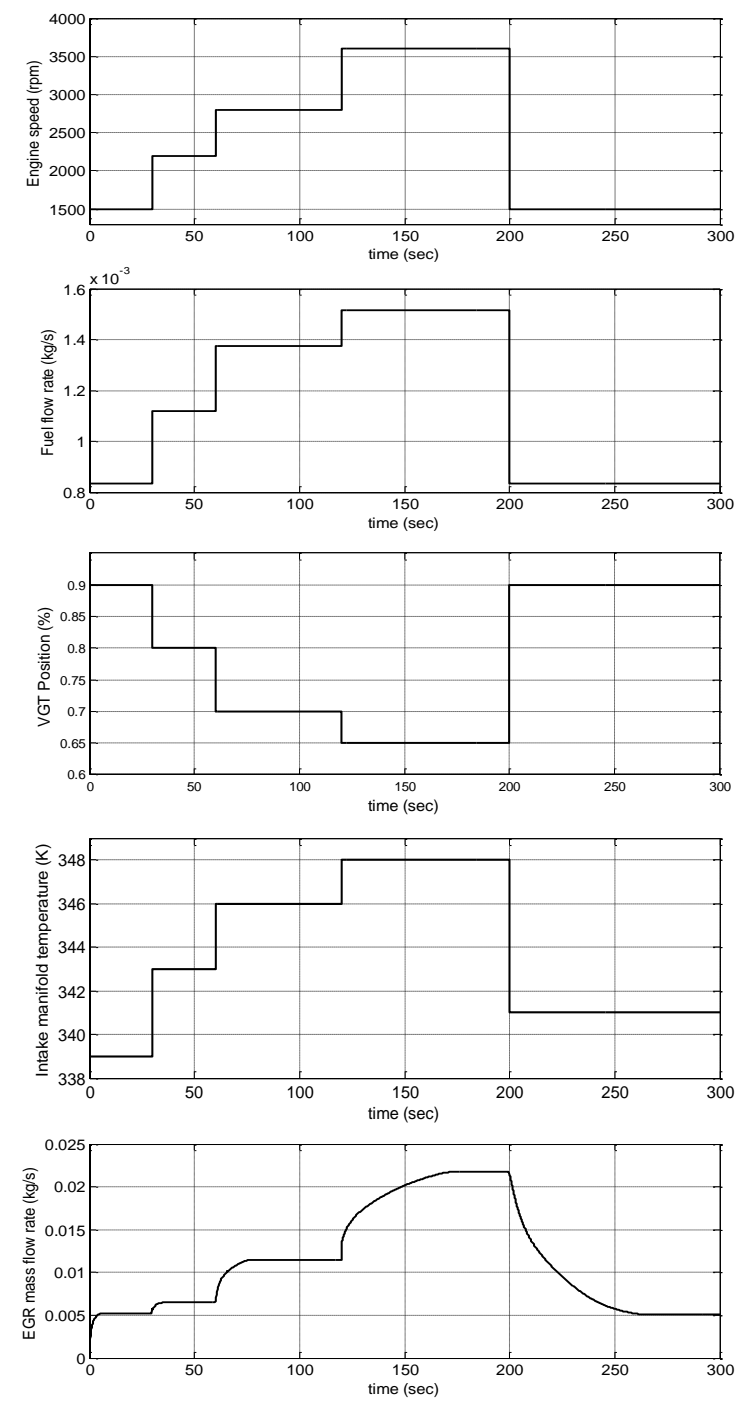

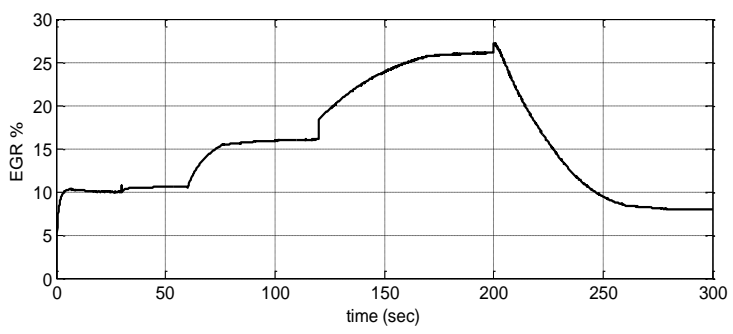

Figure 15 - At 50\% loading effect of variation of engine speed on EGR mass flow rate.

\section{For $80 \%$ loading}
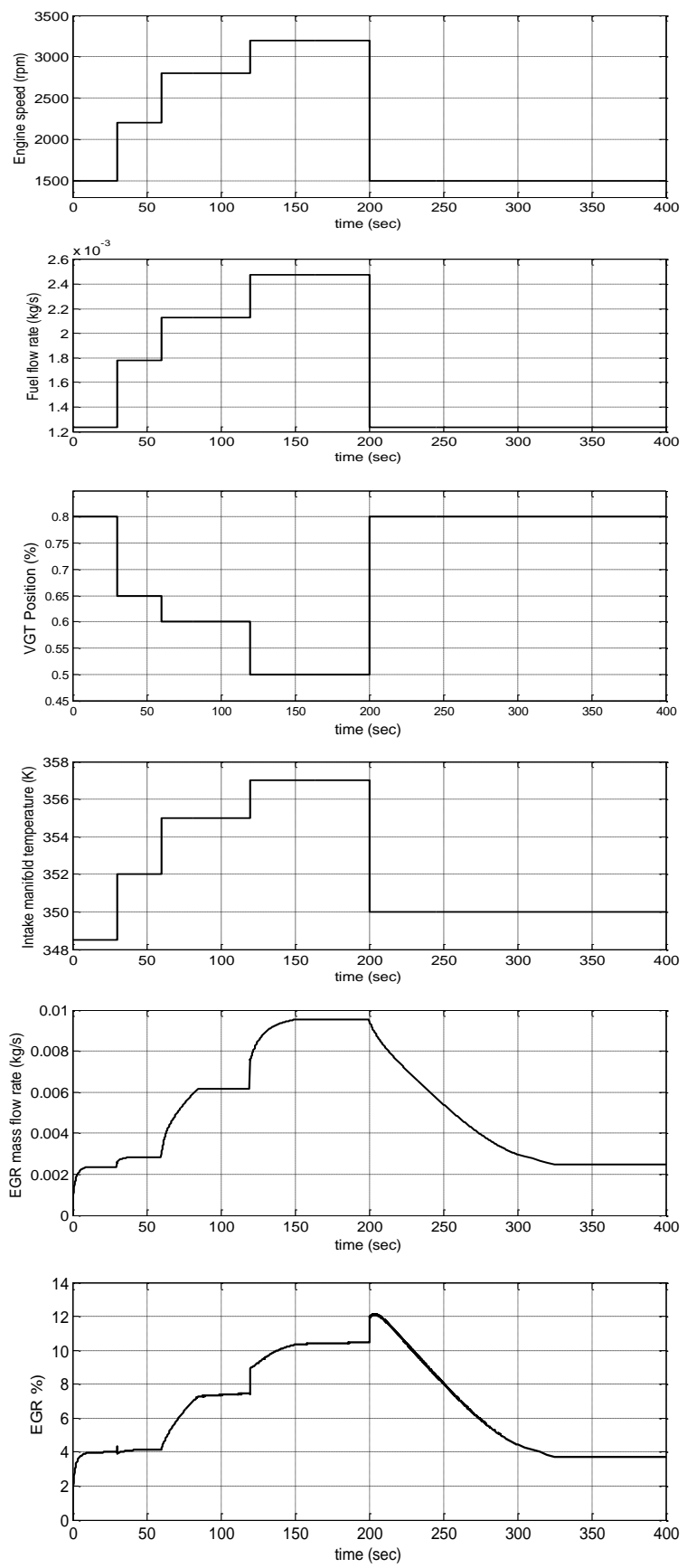

Figure 16 - At $80 \%$ loading effect of variation of engine speed on EGR mass flow rate 


\section{Conclusion}

Physics based model of variable geometry turbocharged diesel engine to estimate EGR mass flow rate and EGR ratio is formulated by combining different subsystems and implemented in MATLAB $^{\text {TM}} /$ SIMULINK $^{\mathrm{TM}}$. The overall model is obtained by coupling the models of individual subsystems of the engines. For simulation, engine specifications are available from manufacturer. Also the experimental data is taken from testing. The overall model is highly complex and nonlinear. Simulation results are shown in graphical and tabular form. Simulation results are presented in the form of line histories of various important physical variables when system is subjected to different loading and to typical steps in engine speed. However based on results and discussion following conclusions are drawn.

- A physics based model developed to estimate EGR mass flow rate consist of five subsystems i.e. intake manifold pressure, exhaust manifold pressure, variable geometry turbocharger, exhaust gas temperature and effective area for EGR valve model.

- $\quad$ The estimated EGR mass flow ratio obtained from a physics based model is varying within the range of 0 to 28 percent at different loading and engine speed. Thus the model presented in this dissertation estimates with acceptable accuracy the EGR mass flow rate and EGR ratio.

- The presented model is simulated for transient engine operating condition, i.e. by sudden increasing and decreasing engine speed.

\section{References}

Motomasa IIZUKA, Naoya KATO, Kenji KASASHIMA, Harufumi MUTO, Carbon Dioxide Measuring Technology in Engine Combustion Chambers, Vol.11 No.6, 2006

P.M. Azzoni, G.Minelli and D. Moro, A model for EGR mass flow rate estimation, SAE Paper No. 970030

Hyunjun Lee, Yeongseop Park, Junsoo Kim, Kangyoon Lee, Myoungho Sunwoo, Development of model based EGR mass flow rate estimation algorithm in a diesel engine, Department of Automotive Engineering, Hanyang University, Seoul 133-791 Korea.

Hyunjin Lee, Yeongseop Park and Seungwoo Hong, EGR rate estimatation for cylinder air charge in a turbocharged diesel engine using an adaptive observer, SAE paper No.2013-01-0246

Ubomír Miklánek, Vojtech Klír, Miloslav Emrich and Ludek Pohorelsky, Thermal Balance Method for EGR Rate Determination Usable for Real Engine with Uncooled EGR System, SAE Paper No 2009-01-1114

Joseph R. Griffin, Chris Ganseman and Chris Baerts Nelson Burkholder, Stephen M. Geyer and Doug Smith, Cooled
EGR Rate Measurement with a Thermal Anemometer for EPA02 Heavy Duty Diesel Engine Emission Control, SAE Paper No. 2003-01-0263

Universal Exhaust Gas Oxygen sensor (UEGO) based measurement of EGR rate and residual gas fraction by Orian Welling and Nick Collings. SAE paper 2011-01-1289

A report on EGR system for diesel engines.

D. N. Malkhede, Mean Value Model and control of a marine turbocharged diesel engine SAE paper No. 2005-01-3889

M. Ammann, N. P. Fekete, L. Guzzella and A. H. Glattfelder, Model based control of the VGT and EGR in a Turbocharged Common-Rail Diesel Engine; Theory and Passenger Car Implementation, SAE Paper No. 2003-01-0357

Internal Combustion Engine Fundamentals by John B Heywood.

A. Mohebbi, S. Jafarmadar and J. Pashae, Performance Evaluation and Emissions improving of Turbocharged DI Diesel Engine with Exhaust Gas Recirculation

Zuhdi Salhab, Effect of Exhaust Gas Recirculation on the Emission and Performance of Hydrogen Fueled SparkIgnition Engine, Global Journal of Researches in Engineering Automotive Engineering Volume 12 Issue 2 Version 1.0 Year 2012

\section{Abbreviations}

\begin{tabular}{|c|c|}
\hline$\dot{m}_{i e}$ & $\begin{array}{l}\text { Mass flow rate of air from intake } \\
\text { manifold to the engine }(\mathrm{kg} / \mathrm{s})\end{array}$ \\
\hline$\dot{m}_{e e}$ & $\begin{array}{l}\text { Mass flow rate of exhaust from engine } \\
\text { to exhaust manifold }(\mathrm{kg} / \mathrm{s})\end{array}$ \\
\hline$\dot{m}_{c}$ & $\begin{array}{l}\text { Mass flow rate through compressor } \\
(\mathrm{kg} / \mathrm{s})\end{array}$ \\
\hline$\dot{m}_{t}$ & Mass flow rate through turbine $(\mathrm{kg} / \mathrm{s})$ \\
\hline $\boldsymbol{m}_{\text {in }}$ & Mass of air in intake manifold (kg) \\
\hline$\dot{\boldsymbol{m}}_{\text {ex }}$ & $\begin{array}{c}\text { Mass flow rate of exhaust gas in the } \\
\text { exhaust manifold (kg) }\end{array}$ \\
\hline$\dot{m}_{\text {air }}$ & Mass flow rate of air $(\mathrm{kg})$ \\
\hline $\mathbf{n}$ & Polytropic constant of air. \\
\hline $\mathbf{n}_{\text {ex }}$ & Polytropic constant of exhaust gas. \\
\hline $\mathbf{R}$ & Gas constant for air (J/kg.K) \\
\hline $\mathbf{R}_{\mathbf{e x}}$ & $\begin{array}{l}\text { Gas constant for exhaust gas constant } \\
\qquad(\mathrm{J} / \mathrm{kg} . \mathrm{K})\end{array}$ \\
\hline Cp & Specific heat of air (J/kg.K) \\
\hline $\mathrm{Cp}_{\mathrm{ex}}$ & Specific heat for exhaust gas (J/kg.K) \\
\hline $\mathbf{M}$ & Torque (N.m) \\
\hline $\mathbf{J}$ & Reduced moment of inertia (kg.m²) \\
\hline
\end{tabular}

\section{Subscripts}

\begin{tabular}{|c|c|}
\hline amb & $\begin{array}{c}\text { Ambient condition/an actual } \\
\text { parameter }\end{array}$ \\
\hline $\mathbf{c}$ & Compressor \\
\hline $\mathbf{e}$ & Engine \\
\hline $\mathbf{e x}$ & Exhaust manifold \\
\hline $\mathbf{i m}$ & Inlet manifold \\
\hline $\mathbf{e}$ & Inlet manifold to engine \\
\hline $\mathbf{e e}$ & Engine to exhaust manifold \\
\hline $\mathbf{t}$ & Turbine \\
\hline $\mathbf{t c}$ & Turbocharger \\
\hline
\end{tabular}

